\title{
Bed Fishing for Florida Bass ${ }^{1}$
}

\author{
John S. Hargrove and James D. Austin ${ }^{2}$
}

Please note: Terms in bold are defined in the glossary section.

\section{Introduction}

Its rapid growth, large maximum size, and acrobatic fighting displays have made Florida bass, Micropterus floridanus (Figure 1) the most popular freshwater sport fish in the state of Florida (USFWS 2011). With nearly 3 million acres of lakes, ponds, and reservoirs plus an additional 12,000 miles of streams and canals, Florida boasts substantial access to pursue and capture trophy-sized bass (Barthel et al. 2015). Anglers in the state of Florida expend considerable effort and money to capture Florida bass, generating about $\$ 1$ billion each year in economic impact via fishing-related expenses such as tackle, boats, and lodging (FWC 2011). Because of the widespread popularity of the fish, Florida devotes significant resources to management of Florida bass populations with the ultimate goal of maintaining healthy bass fisheries for generations to come. A survey of 7,500 freshwater anglers in the state of Florida conducted by the Florida Fish and Wildlife Conservation Commission (FWC) identified bed fishing, the act of fishing for bass as they defend their eggs and young while in the nest, as a conservation concern (FWC 2011).

In 2011, FWC released the Florida Black Bass Management Plan (BBMP), a 20-year science-based and citizen-guided plan to ensure that Florida remains the "Bass fishing capital of the world" (FWC 2011). Direct input from stakeholders including anglers, fishing guides, tackle shop owners, and tournament organizers was a cornerstone of the BBMP. Results from this stakeholder survey identified concerns

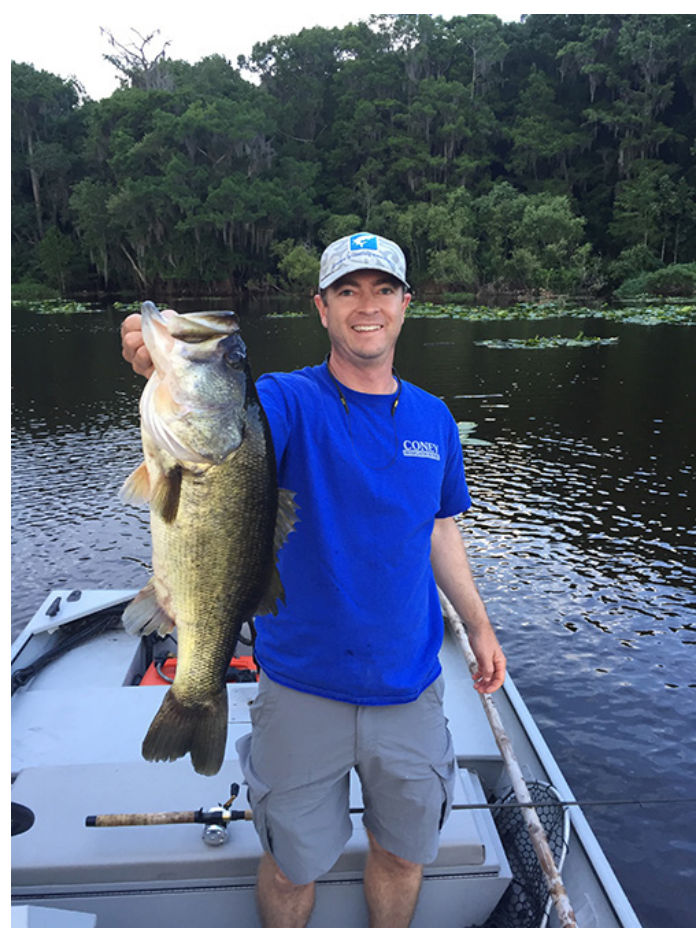

Figure 1. The Florida bass (Micropterus floridanus) is the most widely targeted species of freshwater fish in the state of Florida due in large part to their large maximum size.

Credits: J. Hargrove, UF/IFAS

associated with fishing that targets Florida bass during the reproductive season (bed fishing) as the number two most important issue (after plant management) facing bass fisheries. This fact sheet outlines the reproductive biology of Florida bass, the known consequences of bed fishing, and the best practices that anglers can follow to minimize the impacts of bed fishing.

1. This document is FA204, one of a series of the School of Forest Resources and Conservation, Program in Fisheries and Aquatic Sciences, UF/IFAS Extension. Original publication date May 2018. Visit the EDIS website at http://edis.ifas.ufl.edu.

2. John S. Hargrove, graduate student; and James D. Austin, associate professor; Department of Wildlife Ecology and Conservation, UF/IFAS Extension, Gainesville, FL 32611.

The Institute of Food and Agricultural Sciences (IFAS) is an Equal Opportunity Institution authorized to provide research, educational information and other services

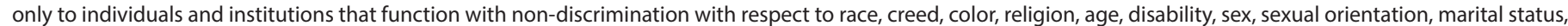

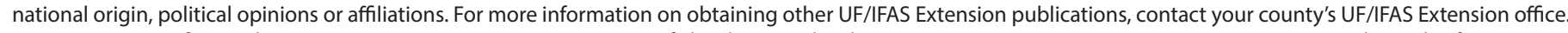
U.S. Department of Agriculture, UF/IFAS Extension Service, University of Florida, IFAS, Florida A \& M University Cooperative Extension Program, and Boards of County Commissioners Cooperating. Nick T. Place, dean for UF/IFAS Extension. 


\section{Reproductive Biology of Florida}

\section{Bass}

Florida bass belongs to the genus Micropterus, which contains 13 species native to eastern North America that are collectively referred to as black bass. Fish in this group all exhibit a form of parental care, which involves the male bass defending their nests from potential predators beginning at the egg stage and ending when their offspring are free swimming. Reproduction in Florida bass begins with male bass forming nests in water 1-2 feet deep as water temperatures warm to $65-70^{\circ} \mathrm{F}$ during the spring (Warren 2009). Bass nests are commonly built near simple cover or submerged objects such as logs, tree limbs, bivalve shells, or cattail roots (Figure 2). Suitable spawning temperatures can be reached as early as December in Lake Okeechobee located in south Florida, but it is more common to see Florida bass on spawning beds between February and April. As one might expect, spawning begins earlier in south Florida than in northern waters because the air and water are warmer. Altogether, the Florida bass spawning season may last up to five months and typically occurs between December and May.

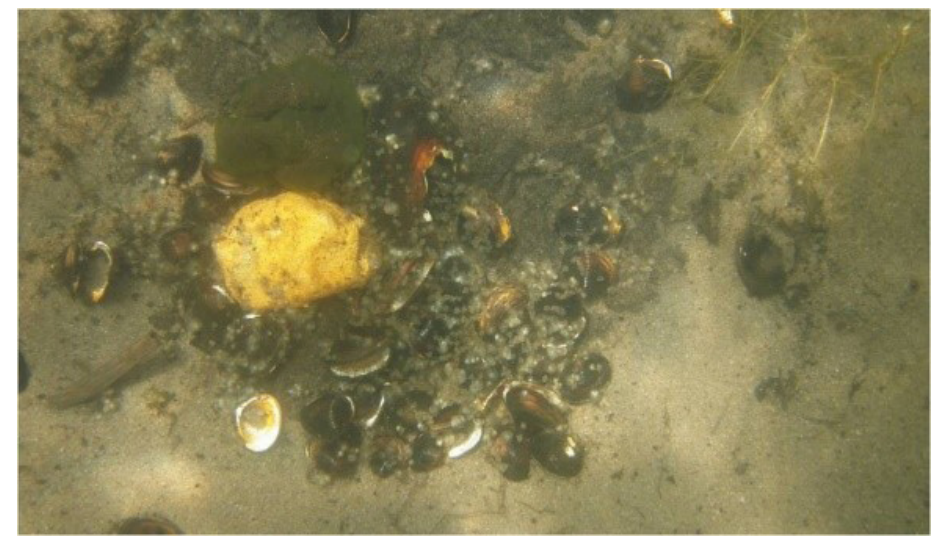

Figure 2. A bass nest. Eggs are visible on and around bivalve shells. Credits: Nicholas Trippel, FWC, used with permission

Once a male bass has finished forming his nest, he will leave it to locate a spawning-ready female and coax her into returning with him to the nest. This courting behavior is thought to take place primarily in the late afternoon (Carr 1942). After the female and male have returned to the nest, the male will use a series of nudges and nips to encourage the female to release her eggs. Males simultaneously release sperm as females lay their eggs, resulting in fertilized eggs being deposited directly into the nest. After fertilization, the male will remain over the nest and guard the fertilized eggs until they develop into free-swimming juveniles, also known as swim-up fry (Figure 3). Females remain on or near the nest for much shorter times than males, typically less than 2 hours. It takes 10 to 11 days for eggs to hatch and grow into fry and subsequently disperse from the nest (Carr 1942). Thus, male Florida bass will remain on the nests for up to two weeks.

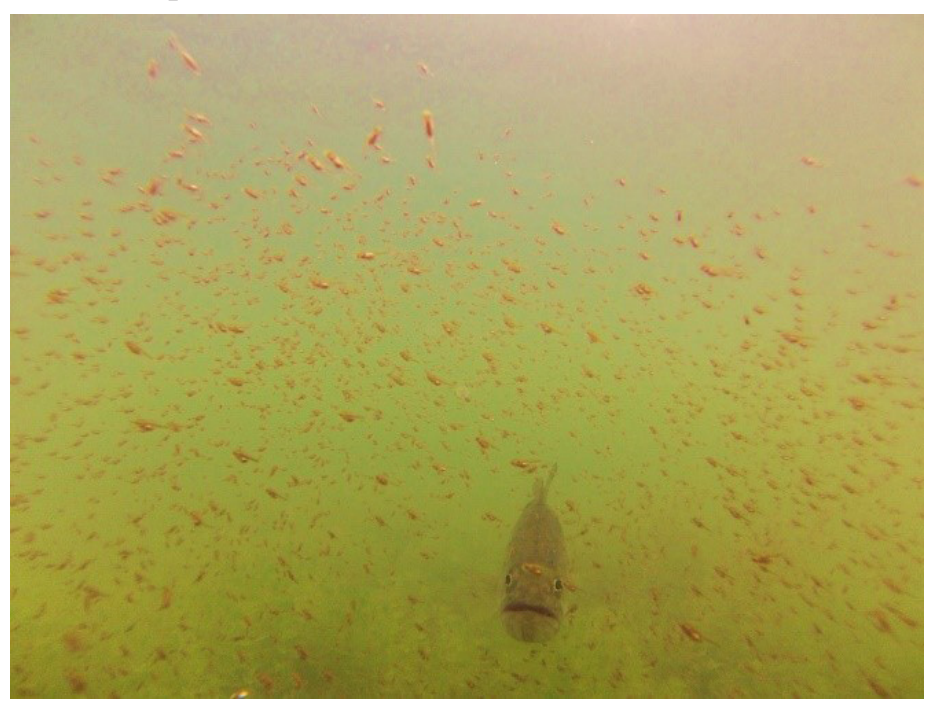

Figure 3. Bass guarding fry.

Credits: Nicholas Trippel, FWC, used with permission

An understanding of the mating system (see glossary) of Florida bass aids an understanding of how bed fishing may impact bass populations. The term "mating system" describes the reproductive behavior of individuals (e.g., how many different mates a male or female has). Much of our current knowledge on the subject has been gleaned from studies in hatchery (Hargrove and Austin 2017) and experimental pond environments (Trippel et al. 2017). For example, genetic analysis revealed that most nests produced in an indoor hatchery involved one male mating with a single female. However, in some cases multiple females contributed eggs to a single nest. Based on visual observation, most pairings between Florida bass in a hatchery setting occurred between a single female and male, although several exceptions were noted. In 1-acre ponds, both males and females mated with multiple distinct partners throughout the spawning period. Males mate with multiple females in two ways. Multiple females may contribute simultaneously to a single nest, or a single male may construct multiple nests and mate with multiple females in the various nests. A consistent observation across studies was that both male and female Florida bass were able reproduce multiple times within a given spawning season with different, unique partners. These characteristics appear to be specific to Florida bass; such behaviors have not been documented in largemouth bass (Micropterus salmoides) or smallmouth bass (M. dolomeiu). The ability of Florida bass to spawn multiple times in one year may make them more resilient than other species of bass to disturbances associated with bed fishing. The loss of a single nesting attempt does not translate to a loss of reproduction within a given year. 


\section{Bed Fishing Explained}

Bed fishing involves the practice of actively targeting a bass while it is on or near the nest guarding its young, either eggs or fry. Because Florida bass guard their nests for up to 2 weeks, this prized sport fish is particularly susceptible to being targeted during the mating season. Florida bass are highly visible to anglers because they are rested over an excavated depression (nest) located in shallow water that is typically less than three feet deep (Figure 4). While defending the nest, male bass are generally aggressive towards nest predators such as bluegill (Lepomis machrocirus) as well as natural and artificial baits that are in or near the nest. It is important to note that male bass cease feeding while on the nest (Hinch and Collins 1991), indicating efforts to remove foreign objects such as lures are done for protective reasons. Anglers commonly report that some fish will aggressively strike lures while others remain noncommittal or shy away from lures or bait. Studies with largemouth bass suggest that males are more likely to strike a lure early in the bedding process when eggs are first deposited into the nest. As fish cease feeding while guarding their nest, a decrease in aggressiveness may be due to a depletion of energy reserves. It has been assumed that bed fishing targets male bass as they protect their young; however, recent work has shown that females may also be captured from the nest (Trippel et al. 2017). Furthermore, female Florida bass reach larger maximum sizes and weights than their male counterparts (Bonvechio et al. 2005). Thus, even though female bass remain on the nests for short periods of time, anglers may preferentially target females on the nest because of their larger size.

\section{Bed Fishing: Cause for Concern or Benign Pastime?}

Bed fishing has received widespread scrutiny due to its documented negative impacts on reproductive success (a term that describes the number of offspring produced by an individual; Philipp et al. 1997). Concerns over the negative impacts of bed fishing for black bass are nothing new. The potential harms associated with bed fishing were first mentioned over 50 years ago (Kramer and Smith 1962). The principle concern associated with bed fishing is that if a nest-guarding bass is captured, predators will consume the unprotected eggs and fry. If substantial numbers of eggs and fry are lost to predation, then the abundance of juvenile bass produced that year may be low. Prolonged reductions in juvenile production could in theory lead to decreases in overall bass numbers because too few new bass would remain to replace the adults that die due to natural or fishing-related causes. Much of the research on bed

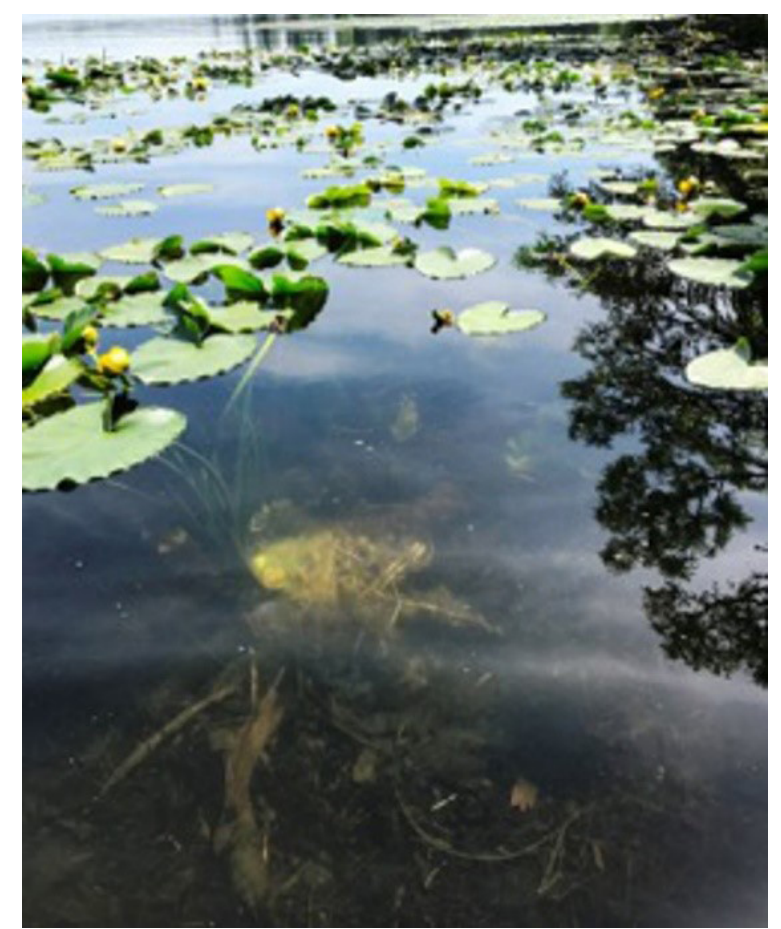

Figure 4. An example of a bass nest formed at the base of aquatic vegetation. Note the lighter color of the substrate in the nest itself, making identification possible for anglers.

Credits: J. Hargrove

fishing impacts has been conducted on the sister species of the Florida bass, the largemouth bass, in northern portions of the United States (Illinois) and southern Ontario (e.g., Philipp et al. 1997). Until recently, it was unknown whether impacts at the individual level, such as the loss of a single nest to bed fishing, scale to population-level harm. That is, does the number of juveniles in subsequent years decline as a result of the loss of one or a few nests?

Several lines of evidence suggest that bed fishing for Florida bass may result in limited harm at the population level. First, in many Florida bass fisheries the majority of captured fish are immediately released, exceeding $80 \%$ in some water bodies (Allen et al. 2008). The general implications for this are as follows: the shorter the amount of time an adult bass is away from the nest the fewer the opportunities predators have to consume eggs and fry. This being said, if most anglers capture a fish and immediately release it, the opportunity for harm is small. Scenarios involving harvest or longer-term retention as in tournaments are more likely to cause nest failure. Scenarios involving both high capture rates and high harvest rates have the potential to measurably reduce juvenile production in bass populations.

A second reason why bed fishing may have minimal impacts on Florida bass populations is the protective characteristics of their physical habitat. Many of the water bodies that Florida bass inhabit are large, contain diverse 
and dense assemblages of aquatic vegetation, and have stained or off-colored water due to suspended algae resulting from high nutrient levels, tannins, or a combination of the two. Large water bodies with complex habitat and limited visibility create a scenario in which a significant number of nesting Florida bass will be neither spotted nor targeted by anglers, reducing the impacts of bed fishing.

Third, individual fish may be able to overcome the loss of an individual nest. As mentioned previously, Florida bass may spawn between December and May, and individual fish may reproduce multiple times within a given year (Hargrove and Austin 2017). Thus, failed nesting attempts early in the season may be compensated for by successful ones later. Recent research showed that bed fishing causes a decline in the percentage of nests that produce fry or juvenile Florida bass (Figure 5). However, populations with lowered nest success produced similar numbers of juveniles and equal numbers of adults contributed to reproduction when compared with populations not subjected to bed fishing (Figure 6).

Mathematical models that simulate the birth and death rates of fish populations provide further evidence to suggest there may be limited population-level harm associated with bed fishing. Simulated bass populations created using data collected from the Florida bass fishery (i.e., typical angler fishing effort, capture rates, release rates, etc.) have shown that seasonal closures would not likely benefit the average fishery. For highly productive systems typical of the southeast United States, those with long growing seasons and high availability of nutrients and bait, large numbers of fish are captured, but few are retained. Together, these conditions would be unlikely to harm bass populations associated with bed fishing.
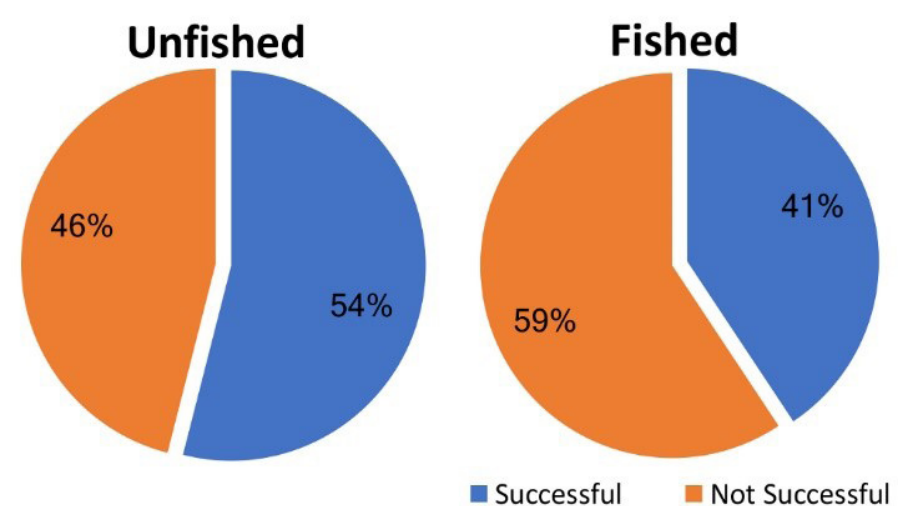

Figure 5. The proportion of successful Florida bass nests in experimental populations subject to a control (unfished) or bed fishing treatment (fished).

Credits: Data from Trippel et al. 2017, reproduced with permission
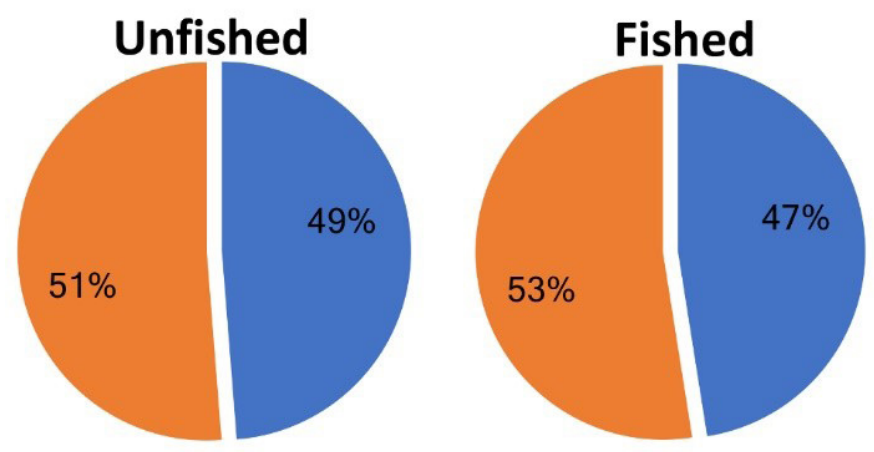

- Successful Not Successful

Figure 6. The proportion of adult Florida bass that contributed successfully to reproduction based on data from experimental populations subject to a control (unfished) or bed fishing treatment (fished).

Credits: Data from Trippel et al. 2017, reproduced with permission

Finally, researchers have identified that the number of juveniles produced in bass populations is stable across a range of adult abundances (Allen et al. 2011; Shaw and Allen 2016). This means that juvenile production does not increase incrementally with each additional adult and therefore there is not a strong linear stock-recruitment relationship for Florida bass (Figure 7). This work identified the presence of recruitment compensation within Florida bass populations, meaning that, when there are low numbers of juveniles, they may experience high survival. Alternatively, when juvenile abundances are very high, they may suffer low survival. Thus, higher survival of eggs does not equate to more juveniles, and losses of eggs due to bed fishing will not necessarily result in fewer juveniles the following year.

Some evidence indicates, then, that responsibly managed bed fishing may not cause Florida bass populations to decline. Not all bed fishing is harmless, however. In particular, catch-and-kill practices or tournament fishing wherein bass are moved away from their nests to a weigh station may result in individual population declines. According to a recent survey of over 400 anglers, just over half of all anglers spent half or more of their springtime trips fishing for bedding bass. If large numbers of tournaments were to draw hundreds of anglers consistently throughout the spawning season on small lake systems, it remains possible that transferring significant quantities of fish from spawning areas to the weigh-in may lead to disrupted reproduction. Whether non-tournament recreational angling could cause similar declines is unknown. As a result of this uncertainty, the potential consequences of retaining bedding bass in competitive tournaments requires further study. An additional scenario wherein bed fishing may cause harm involves small populations. Populations 


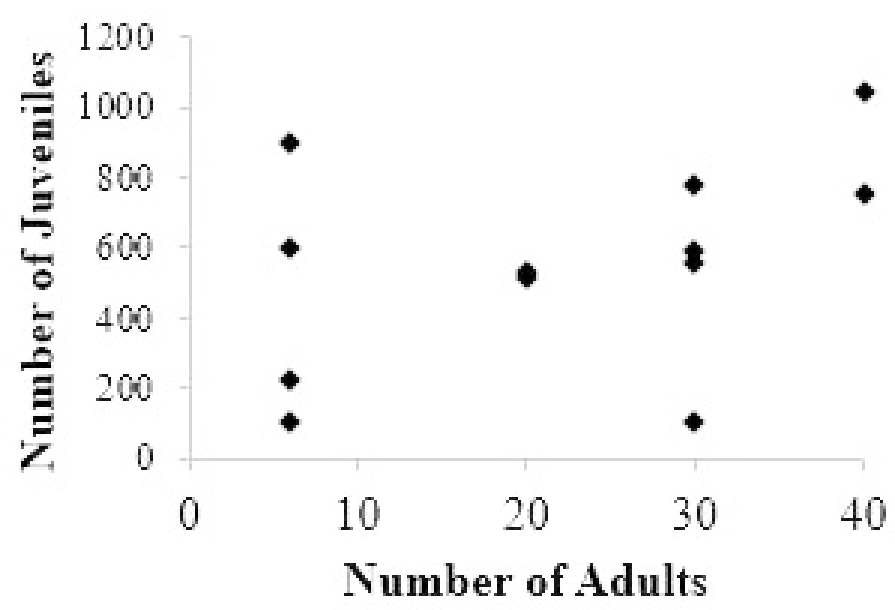

Figure 7. The number of juveniles produced across 12 experimental populations of Florida bass in which the number of adults was intentionally manipulated.

Credits: Reproduced with permission from Allen et al. 2011

of Florida bass that produce less than two successful nests per acre, as might occur in small ponds or lakes, are likely to experience significant declines in juvenile production. So, if bed fishing reduces the number of successful nests to less than two per acre, then negative changes may result. Ultimately, there are several scenarios that require further study in order to better understand how bed fishing affects Florida bass populations. For a quick list of actions that anglers can take to minimize the chances of bed fishing resulting in undue harm, see Table 1.

\section{Summary}

Based on information gathered from experimental studies, simulation models, and the natural history of Florida bass, it appears possible that the impacts of catch-and-release angling for bedding bass may negatively impact individual nest success. However, under many circumstances these changes will not elicit negative effects at the population level. Previous studies have shown the topic of bed fishing to be controversial, with many anglers holding deeply opposed views on the potential harms associated with this fishing tactic (Hargrove et al. 2018). Future studies are needed to understand the manner and extent to which bass populations are affected by different forms of bed fishing (e.g., recreational anglers vs. tournaments). Ultimately, the decision of whether or not to bed fish remains the choice of the individual angler; however, current scientific knowledge supports the argument that individual nests but not overall populations of Florida bass may be harmed by bed fishing, except in extreme circumstances.

\section{Glossary}

Recruitment compensation-refers to a density-dependent feedback interaction in which the number of juveniles produced per parent varies as a function of population density. In other words, juvenile survival may be highest when population sizes are small and lowest when population sizes are large. The end result is that similar numbers of offspring may survive despite significant differences in the number of eggs that are produced.

Mating system - the reproductive behavior of a given species that includes how many different mates a male or female will obtain within a given spawning season.

Stock-recruitment relationship-the connection between the abundance of sexually mature adults in a population and the number of juvenile fish that are produced and reach a certain size or age (e.g., numbers of offspring that survive through the first year of life).

\section{References}

Allen, M. S., C. J. Walters, and R. Myers. 2008. “Temporal Trends in Largemouth Bass Mortality, with Fishery Implications." North American Journal of Fisheries Management 28(2):418-427.

Allen, M. S., M. W. Rogers, M. J. Catalano, D. G. Gwinn, and S. J. Walsh. 2011. "Evaluating the Potential for Stock Size to Limit Recruitment in Largemouth Bass." Transactions of the American Fisheries Society 140:1093-1100.

Barthel, B. L., M. S. Allen, W. F. Porak, and J. Kerns. 2015. "Florida Bass Micropterus floridanus (Lesueur, 1822)." In: Tringali, M. D., J. M. Long, T. W. Birdsong, and M. S. Allen, editors. Black bass diversity: multidisciplinary science for conservation. American Fisheries Society Symposium 82. Bethesda (MD): American Fisheries Society. p. 44-54.

Bonvechio, T. F., M. S. Allen, and R. L. Cailteux. 2005. "Relative Abundance, Growth, and Mortality of Suwannee Bass in Four Florida Rivers." North American Journal of Fisheries Management 25(1):275-283.

Carr, M. H. 1942. “The Breeding Habits, Embryology and Larval Development of the Largemouthed Black Bass in Florida." Proceedings of the New England Zoological Club 20:43-77.

Florida Fish and Wildlife Conservation Commission (FWC). 2011. Black bass management plan. (updated 5/1/2011). http://myfwc.com/fishing/freshwater/blackbass/. Accessed: August 28, 2017. 
Hargrove, J. S., and J. D. Austin. 2017. "Parentage and Mating Patterns in a Florida Largemouth Bass (Micropterus salmoides floridanus) Hatchery." Aquaculture Research 48:3272-3277.

Hargrove, J. S., M. S. Allen, O. L. F. Weyl, C. A. C. Crandall, and J. D. Austin. 2018. "Global Patterns in the Motivations and Behaviors of Tournament Anglers Targeting Bedding Bass." North American Journal of Fisheries Management. doi:10.1002/nafm.10027

Hinch, S. G., and N. C. Collins. 1991. "Importance of Diurnal and Nocturnal Nest Defense in the Energy Budget of Male Smallmouth Bass: Insights from Direct Video Observations." Transactions of the American Fisheries Society 120(5):657-663.

Kramer, R. H., and L. L. Smith. 1962. "Formation of Year Classes in Largemouth Bass." Transactions of the American Fisheries Society 91(1):29-41.

Philipp, D. P., C. A. Toline, M. F. Kubacki, D. B. F. Philipp, and F. J. S. Phelan. 1997. "The Impact of Catch-and-Release Angling on the Reproductive Success of Smallmouth Bass and Largemouth Bass." North American Journal of Fisheries Management 17(2):557-567.

Shaw, S. L., and M. S. Allen. 2016. "Quantifying Recruitment Compensation in Florida Largemouth Bass, with Implications for Fisheries." Transactions of the American Fisheries Society 145(3):462-475.

Trippel, N., J. S. Hargrove, E. H. Leone, J. D. Austin, and M. S. Allen. 2017. "Angling-Induced Impacts on Recruitment and Contributions to Reproduction in Florida Bass." Transactions of the American Fisheries Society. 146:871-887.

U.S. Department of the Interior, Fish and Wildlife Service, and U. S. Department of Commerce, U. S. Census Bureau. 2011. National survey of fishing, hunting, and wildlifeassociated recreation. U.S. Fish and Wildlife Service, Washington.

Warren Jr, M. 2009. "Centrarchid Identification and Natural History." Pages 375-481 in S. Cooke, and D. Philipp, editors. Centrarchid Fishes Diversity, Biology and Conservation. John Wiley \& Sons, West Sussex, UK. 
Table 1. A quick list of "dos and don'ts" to minimize the effects of angling on Florida bass breeding populations.

\begin{tabular}{|c|c|}
\hline Do & Don't \\
\hline $\begin{array}{l}\text { Practice catch-and-release } \\
\text { Minimize time spent handling the fish } \\
\text { Limit behaviors that will result in the removal of fish scales and } \\
\text { slime coat } \\
\text { Avoid excessive handling such as pulling fish into the boat and } \\
\text { resting them on carpet } \\
\text { Have your camera ready so that trophy fish can be } \\
\text { photographed and released quickly } \\
\text { Return fish to the same area where they were captured } \\
\text { Use tackle (line and rod) of sufficient strength to quickly land a } \\
\text { fish }\end{array}$ & $\begin{array}{l}\text { Harvest fish captured from spawning beds beds } \\
\text { Hold fish out of water for prolonged periods of time (more than a minute) } \\
\text { Rest or handle fish in a manner that will remove scales } \\
\text { Slowly reel in fish or fight fish until they are exhausted } \\
\text { Bed fish routinely in small populations where it is likely an angler could } \\
\text { catch all/nearly all spawning adults }\end{array}$ \\
\hline
\end{tabular}

